Check for updates

Cite this: Chem. Sci., 2019, 10, 6642

๑ All publication charges for this article have been paid for by the Royal Society of Chemistry

Received 29th March 2019

DOI: $10.1039 / \mathrm{c} 9 \mathrm{sc} 01538 \mathrm{~h}$

rsc.li/chemical-science
Accepted 28th May 2019

\section{Exclusive occurrence of photoinduced energy transfer and switching of its direction by rectangular $\pi$-extension of nanographenes $\dagger$}

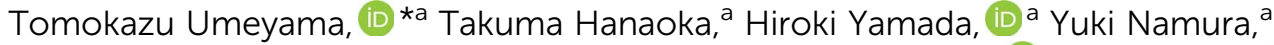 \\ Satoshi Mizuno, ${ }^{a}$ Tomoya Ohara, ${ }^{a}$ Jinseok Baek, ${ }^{a}$ JaeHong Park, (D) a Yuta Takano, (D) ${ }^{b}$ \\ Kati Stranius, (D) ${ }^{c}$ Nikolai V. Tkachenko (D) *c and Hiroshi Imahori (iD)*ab
}

\begin{abstract}
As structure defined cutouts of the graphene lattice, nanographene molecules have gained plenty of attention because of their high potential for versatile applications in organic electronics and energy conversion devices and as ideal model systems for the better understanding of intrinsic structureproperty correlations of graphenes. In this study, well-defined nanographenes with $\mathrm{sp}^{2}$ carbon networks of different sizes, hexa-peri-hexabenzocoronene (HBC) and its rectangularly $\pi$-extended version, a short graphene nanoribbon (GNR), have been covalently functionalized with photoactive porphyrin molecules. On the basis of their spectroscopic studies, the photodynamics of the porphyrin-linked nanographenes was found to be influenced substantially by the size of the nanographenes. Photoexcitation of the porphyrin-HBC linked system led to exclusive energy transfer (EnT) from the first singlet excited state $\left(\mathrm{S}_{1}\right)$ of the nanographene to the porphyrin, whereas opposite selective EnT occurred from the first and second singlet excited states $\left(S_{1}\right.$ and $\left.S_{2}\right)$ of the porphyrin to the nanographene in the porphyrin-GNR linked system. In particular, ultrafast efficient EnTs from both the $S_{2}$ and $S_{1}$ states of the porphyrin to GNR mimic the corresponding ultrafast EnTs from the $S_{2}$ and $S_{1}$ states of carotenoids to chlorophylls in light-harvesting systems of natural photosynthesis. Such unique photophysical properties will be useful for the rational design of carbon-based photofunctional nanomaterials for optoelectronics and solar energy conversion devices.
\end{abstract}

\section{Introduction}

Nanographenes, characterized by well-defined planar structures of $\mathrm{sp}^{2}$ carbon networks with sizes over $1 \mathrm{~nm}$, have attracted tremendous attention, ${ }^{1}$ as their extended $\pi$-conjugation offers intriguing characteristics in optical and electronic properties, such as large extinction coefficients, high photoluminescence quantum yields, and excellent charge transport abilities. ${ }^{2-4}$ These properties suggest their potential utility as basic components in various electronic devices including lightemitting diodes, solar cells, and field-effect transistors. ${ }^{5-8}$ Along this line, nanographenes with different sizes and edge configurations have been prepared, demonstrating the possibility of fine-tuning their electronic and optoelectronic

${ }^{a}$ Department of Molecular Engineering, Graduate School of Engineering, Kyoto University, Nishikyo-ku, Kyoto, 615-8510, Japan. E-mail: umeyama@scl.kyoto-u.ac. jp; imahori@scl.kyoto-u.ac.jp

${ }^{b}$ Institute for Integrated Cell-Material Sciences (WPI-iCeMS), Kyoto University, Sakyoku, Kyoto 606-8501, Japan

'Faculty of Engineering and Natural Sciences, Tampere University, Korkeakoulunkatu 8, 33720 Tampere, Finland. E-mail: nikolai.tkachenko@tuni.fi

$\dagger$ Electronic supplementary information (ESI) available. See DOI: $10.1039 / \mathrm{c} 9 \mathrm{sc} 01538 \mathrm{~h}$ properties through structural modulation. ${ }^{1}$ Among them, hexaperi-hexabenzocoronenes (HBCs) consisting of $42 \mathrm{sp}^{2}$ carbons in the $\pi$-conjugated core can be regarded as the minimum unit of nanographenes. ${ }^{1,9}$ In contrast to nanographene molecules, other two-dimensional (2D) nanocarbons such as graphenes, graphene oxides (GOs), chemically converted graphenes (CCGs), and graphene quantum dots (GQDs) are structurally inhomogeneous at the molecular level, containing different $\pi$-conjugation sizes, edge structures, and defect sites. ${ }^{10}$ Nanographenes can be regarded as part of larger $2 \mathrm{D}$ nanocarbons, and therefore, $\pi$-extended HBC derivatives with well-defined structures are ideal model units to understand the intrinsic structureproperty correlations of the $2 \mathrm{D}$ nanocarbons. ${ }^{1}$

Covalent linking of nanographenes and photoactive molecules is an effective strategy to endow them with new functions, as well as to examine their optical and photophysical properties, without changing the nanographene core structures. ${ }^{11-14}$ Various HBC linked systems with photoactive molecules including porphyrins,${ }^{11}$ perylene diimides,${ }^{12}$ and fullerenes ${ }^{13}$ were prepared and their basic optical properties such as steady-state absorption and fluorescence spectra were investigated. Nevertheless, so far such covalent functionalization of nanographenes has been limited to HBCs solely, and, to the best of our knowledge, 
covalently linked systems of photoactive molecule-nanographenes larger than HBC have never been reported. Therefore, the size and shape effects of nanographenes on the optical and photophysical properties of nanographene-photoactive molecule linked systems have yet to be studied systematically.

To this end, we employed two nanographenes as models: the symmetrical HBC and its $\pi$-extended rectangular strip-shaped nanographene consisting of $114 \mathrm{sp}^{2}$ carbons,,$^{15}$ which is a short graphene nanoribbon (GNR). They were linked with two zincporphyrin $(\mathrm{ZnP})$ units through a $p$-phenylene bridge at the periphery positions (Scheme 1) for the better understanding of their intrinsic properties. The short, rigid phenylene spacer ensures a well-defined geometry between the nanographene and the attached porphyrins. Hereafter, the HBC and GNR reference molecules are denoted as HBC-ref and GNR-ref, and the porphyrin linked systems with HBC-ref and GNR-ref are referred to as ZnP-HBC and ZnP-GNR (Scheme 1). To improve their solubility in organic solvents, long alkyl chains were introduced into the HBC and GNR moieties. The HBC core was selected as a typical, basic example of nanographenes. ${ }^{1,9}$ Although various linked systems of HBC with photoactive molecules including porphyrins have already been reported, ${ }^{11-14}$ ZnP-HBC linked systems with a $p$-phenylene spacer have yet to be synthesized. Meanwhile the GNR core was chosen because of its closely related structure to HBC. GNR possesses the same size on the short axis, but a large size on the long axis compared to HBC. Furthermore, GNR and HBC have the same edge structures, which provides an opportunity to focus on the size effect of nanographenes. ${ }^{15 a}$ The symmetric extension of the $\pi$-conjugation network of HBC in a regular hexagon shape would be another option, but even the synthesis is a great challenge. ${ }^{1,4 c, 16}$ Both HBC-ref and GNR-ref possess two reactive $\mathrm{C}-\mathrm{H}$ groups at less sterically hindered positions, ${ }^{17}$ which are useful for introducing the porphyrin units regioselectively (Scheme 1).

Nanocomposites of porphyrins with 2D nanocarbons such as graphenes, GOs, CCGs, and GQDs have been synthesized because of their potential applications in photoelectrochemical devices, photocatalysts, photodynamic and photothermal therapies, and biosensors. ${ }^{18-21}$ To achieve synergistic effects of the combinations of porphyrins and $2 \mathrm{D}$ nanocarbons on their performances in the applications, the occurrence of efficient photoinduced energy transfer (EnT) or electron transfer (ET) from the attached porphyrins to the $2 \mathrm{D}$ nanocarbons or vice versa is of extreme importance. Systematic investigations on porphyrin-2D nanocarbon covalently linked systems revealed that their photodynamics is profoundly affected by the spacer structures that govern separation distances and mutual orientations between porphyrins and 2D nanocarbons. ${ }^{22-24}$ However, 2D nanocarbons in the porphyrin-linked systems reported so far consist of complicated mixtures with a range of sizes, shapes, and defects of the $\mathrm{sp}^{2}$ carbon network. In addition, the attachment positions of the porphyrins on the $2 \mathrm{D}$ nanocarbons, i.e., the center or the edge of the $\mathrm{sp}^{2}$ carbon network, are nonuniform. These factors may also exert a significant influence on the interaction between porphyrins and 2D nanocarbons in the excited states. In contrast to the porphyrin-2D nanocarbon linked systems, ZnP-HBC and ZnP-GNR in the present study have well-defined molecular structures. Therefore, they are excellent model systems to investigate the intrinsic photophysical properties of porphyrin-2D nanocarbon nanocomposite materials. Furthermore, the porphyrinnanographene linked molecules themselves are excellent candidates as photoactive materials in the above practical applications. Nevertheless, the detailed photophysical

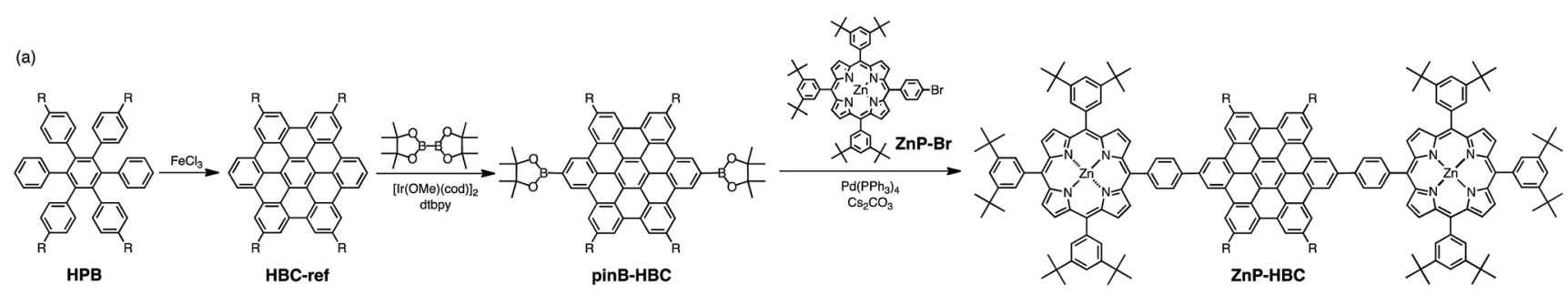

(b)
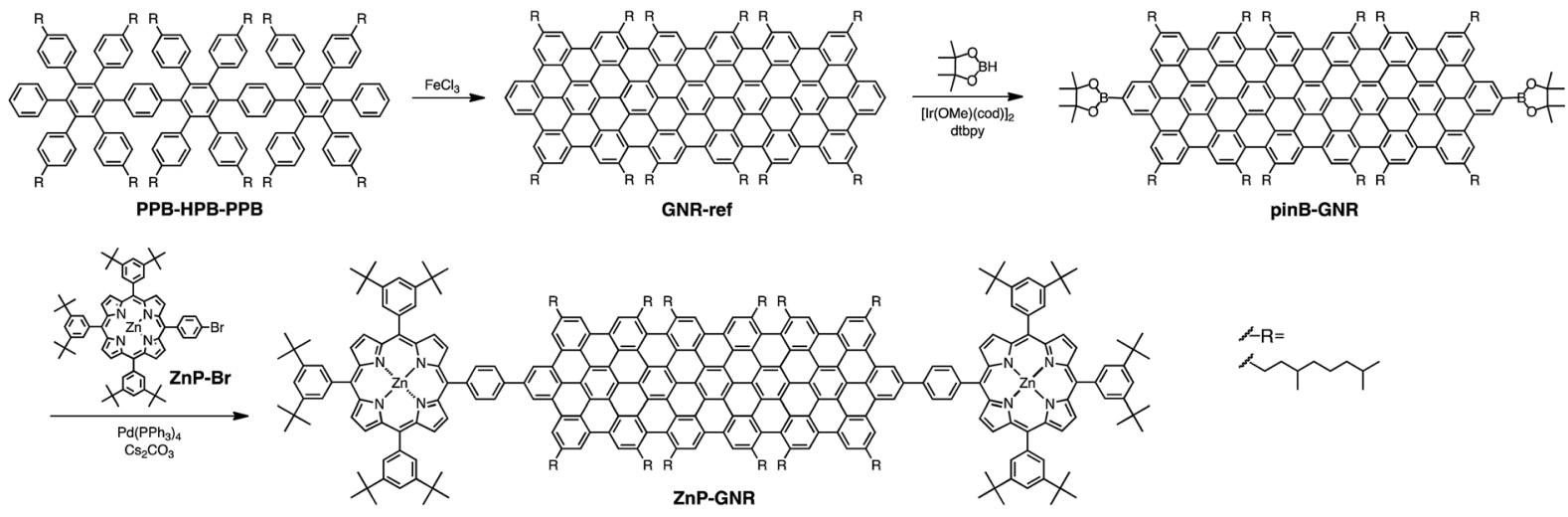

Scheme 1 Synthetic procedures for (a) ZnP-HBC and (b) ZnP-GNR. 
properties of previously synthesized porphyrin-linked HBC molecules have not been scrutinized using time-resolved spectroscopy. ${ }^{\mathbf{1 1}}$ Herein, we report the photophysical properties of $\mathrm{ZnP}-\mathrm{HBC}$ and $\mathrm{ZnP}-\mathrm{GNR}$. The size increase in the nanographenes was found to switch the EnT direction together with the exclusive occurrence of photoinduced EnT.

\section{Experimental}

\section{Instruments}

NMR spectra were measured with a JEOL JNM-EX400 NMR spectrometer or JEOL JNM-AL300 NMR spectrometer. Attenuated total reflectance (ATR) FT-IR spectra were recorded on a Thermo Fisher Scientific Nicolet 6700 FT-IR. High-resolution mass spectra (HRMS) were obtained with a Thermo Fisher Scientific EXACTIVE. UV-visible absorption spectra were measured with a PerkinElmer Lambda 900 UV/vis/NIR spectrometer. Steady-state fluorescence spectra were recorded on a HORIBA SPEX Fluoromax-3 spectrofluorometer. Phosphorescence spectra were measured on a HORIBA NanoLOG-TCSPC at 77 K. Cyclic voltammetry (CV) and differential pulse voltammetry (DPV) measurements were performed using an ALS 630A electrochemical analyzer in THF containing $0.1 \mathrm{M}$ tetra- $n$ butylammonium hexafluorophosphate $\left(\mathrm{Bu}_{4} \mathrm{PF}_{6}\right)$ as a supporting electrolyte. Time-correlated single photon counting (TCSPC) measurements using a HORIBA NanoLOG-TCSPC were conducted for fluorescence lifetime measurements on the nanosecond and subnanosecond time-scale. The time resolution was ca. 200 ps. Ultrafast fluorescence decays were measured using a photon up-conversion method described in detail elsewhere, ${ }^{25}$ with a temporal resolution of $c a .150 \mathrm{fs}$. In brief, fundamental pulses of $810 \mathrm{~nm}$ produced by a Ti:sapphire laser (TiF50, CDPAvesta) at an $80 \mathrm{MHz}$ repetition rate were split into two beams. One portion underwent second harmonic generation to excite the sample at 405 or $425 \mathrm{~nm}$, generating emission. Pump-probe measurements were performed using Libra-F (Coherent) and Topas-C (Light Conversion) laser systems to produce pump and probe pulses and an ExciPro (CDP) measurement system to record the time-resolved absorption spectra. ${ }^{26}$ Typically, the time resolution of the instrument was 150 fs. Transient absorption measurements for nanoseconds to microseconds were carried out with a laser system provided by Unisoku according to the following procedure: a sample solution was excited using a Panther optical parametric oscillator pumped by a Nd:YAG laser (Continuum, Surelite SLI-10; 4-6 ns fwhm) at $\lambda=$ $410 \mathrm{~nm}$. The photodynamics was monitored by continuous exposure to a Xe lamp as a probe light and a photomultiplier tube (Unisoku, PMT for 440-780 nm) and a photodiode (Unisoku, NIR-PD1 for 780-1100 nm) as detectors. The output from the photodiode and photomultiplier tube was recorded with a digitizing oscilloscope (Iwatsu, Digital Oscilloscope DS-5532).

\section{Theoretical calculations}

Geometry optimization and electronic structure calculations were performed using density functional theory (DFT) at the spin-restricted B3LYP/6-31G level. Calculations were carried out using the Gaussian 09 program. ${ }^{27}$ All structures were fully optimized without any symmetry restriction.

\section{Synthesis}

All solvents and chemicals were of reagent grade quality, purchased and used without further purification. Synthetic details of oligo( $p$-phenylene)s HPB and PPB-HPB-PPB (Scheme 1) are described in the ESI. $\uparrow$ The abbreviations of compounds are defined in Scheme 1 and the ESI. $\dagger$

HBC-ref. To HPB (285 mg, $0.260 \mathrm{mmol}$ ) in dichloromethane $(50 \mathrm{~mL})$ was added $\mathrm{FeCl}_{3}(843 \mathrm{mg}, 5.20 \mathrm{mmol})$ in $\mathrm{CH}_{3} \mathrm{NO}_{2}(2 \mathrm{~mL})$ under an argon atmosphere. The reaction mixture was stirred at room temperature for $1 \mathrm{~h}$. The reaction was quenched with methanol, and the solvent was removed under vacuum. The solid residue was purified by column chromatography $\left(\mathrm{SiO}_{2}\right.$, chloroform), yielding HBC-ref as a yellow solid (207 mg, $0.191 \mathrm{mmol}, 74 \%) .{ }^{1} \mathrm{H}$ NMR (300 $\left.\mathrm{MHz}, \mathrm{CDCl}_{3}\right) \delta 8.07$ (d, $J=$ $7.7 \mathrm{~Hz} 4 \mathrm{H}), 7.84$ (d, $J=12.8 \mathrm{~Hz} 10 \mathrm{H}), 2.68$ (m, 8H), 1.67-0.87 (m, $76 \mathrm{H}) .{ }^{13} \mathrm{C}$ NMR (75.45 MHz, $\left.\mathrm{C}_{2} \mathrm{D}_{2} \mathrm{Cl}_{4}, 393 \mathrm{~K}\right) \delta: 140.3,129.5$, 125.5, 124.6, 122.8, 121.0, 119.9, 39.4, 37.3, 34.4, 33.0, 29.4, 27.8, 24.7, 22.4, 19.2. IR (ATR): 2955, 2924, 2905, 2868, 1612, 1585, $1465,1376,844 \mathrm{~cm}^{-1}$. HRMS (MALDI-TOFMS, $\left.m / z\right)=1083.7729$ $\left(\mathrm{M}+\mathrm{H}^{+}\right)$; calcd for $\mathrm{C}_{82} \mathrm{H}_{98}$ : 1082.7668 .

pinB-HBC. To HBC-ref $\left(15.6 \mathrm{mg}, 1.44 \times 10^{-2} \mathrm{mmol}\right)$ and bis(pinacolato)diboron (49.4 $\mathrm{mg}, 0.195 \mathrm{mmol}$ ) in mesitylene $(0.75 \mathrm{~mL})$ and tert-butyl methyl ether $(0.65 \mathrm{~mL})$ were added $4,4^{\prime}$ di-tert-butyl-2,2'-bipyridyl (dtbpy, $3.3 \mathrm{mg}, 1.2 \times 10^{-2} \mathrm{mmol}$ ) and $[\mathrm{Ir}(\mathrm{OMe}) \mathrm{cod}]_{2}\left(3.9 \mathrm{mg}, 5.9 \times 10^{-3} \mathrm{mmol}\right.$, cod $=$ cycloocta-1,5diene) under an argon atmosphere. The reaction mixture was heated at $80{ }^{\circ} \mathrm{C}$ with stirring for $48 \mathrm{~h}$. The mixture was washed with water, extracted with dichloromethane and dried with $\mathrm{MgSO}_{4}$. Then, solvent was removed under vacuum and the solid residue was reprecipitated (dichloromethane/methanol), yielding a yellow solid. The crude product $(5.7 \mathrm{mg})$ was used without further purification in the next step.

ZnP-HBC. To ZnP-Br (10.6 mg, $\left.9.72 \times 10^{-3} \mathrm{mmol}\right)$ and pinB-HBC $(5.7 \mathrm{mg})$ in toluene $(1 \mathrm{~mL})$ were added $\mathrm{Pd}\left(\mathrm{PPh}_{3}\right)_{4}$ $\left(0.8 \mathrm{mg}, 7 \times 10^{-4} \mathrm{mmol}\right)$ and $\mathrm{Cs}_{2} \mathrm{CO}_{3}\left(15.6 \mathrm{mg}, 4.79 \times 10^{-2}\right.$ $\mathrm{mmol}$ ) under an argon atmosphere. The reaction mixture was heated at $100{ }^{\circ} \mathrm{C}$ with stirring for $24 \mathrm{~h}$. The mixture was washed with water, extracted with dichloromethane and dried with $\mathrm{MgSO}_{4}$. Then, solvent was removed under vacuum and the solid residue was purified by column chromatography $\left(\mathrm{SiO}_{2}\right.$, dichloromethane : hexane $=1: 2$ ) and gel permeation chromatography (toluene), yielding $\mathrm{ZnP}-\mathrm{HBC}$ as a deep purple solid (2.4 mg, $\left.7.7 \times 10^{-4} \mathrm{mmol}, 18 \%\right) .{ }^{1} \mathrm{H} \mathrm{NMR} \mathrm{(400} \mathrm{MHz}, \mathrm{CDCl}_{3}, 333$ K) $\delta 9.50(\mathrm{~s}, 4 \mathrm{H}), 9.30-9.27(\mathrm{~m}, 4 \mathrm{H}), 9.12-9.01(\mathrm{~m}, 12 \mathrm{H}), 8.89(\mathrm{~s}$, $4 \mathrm{H}), 8.64(\mathrm{t}, J=16.6 \mathrm{~Hz} 4 \mathrm{H}), 8.57(\mathrm{~s}, 4 \mathrm{H}), 8.16-8.12(\mathrm{~m}, 12 \mathrm{H})$, $7.81(\mathrm{~s}, 6 \mathrm{H}), 7.35(\mathrm{~d}, J=3.44 \mathrm{~Hz} 4 \mathrm{H}), 3.29(\mathrm{~m}, 8 \mathrm{H}), 2.34-0.74(\mathrm{~m}$, 130H). IR (ATR): 2950, 2876, 1714, 1442, 1362, 1261, 1182, 1092, 1039, 921, $805 \mathrm{~cm}^{-1}$. HRMS (MALDI-TOFMS, $\mathrm{m} / z$ ) $=3103.8039$ $\left(\mathrm{M}^{\cdot+}\right)$; calcd for $\mathrm{C}_{218} \mathrm{H}_{246} \mathrm{~N}_{8} \mathrm{Zn}_{2}$ : 3103.8078 .

GNR-ref. To PPB-HPB-PPB (13.2 $\left.\mathrm{mg}, 4.22 \times 10^{-3} \mathrm{mmol}\right)$ in dichloromethane $(18 \mathrm{~mL})$ was added $\mathrm{FeCl}_{3}(120 \mathrm{mg}, 0.740$ mmol) in $\mathrm{CH}_{3} \mathrm{NO}_{2}(1.3 \mathrm{~mL})$ under an argon atmosphere. The reaction mixture was warmed at $35^{\circ} \mathrm{C}$ with stirring for $15 \mathrm{~min}$. 
The reaction was quenched with methanol, and solvent was removed under vacuum. The solid residue was purified by column chromatography $\left(\mathrm{SiO}_{2}\right.$, chloroform) and gel permeation chromatography (toluene), yielding GNR-ref as a purple solid (4.3 mg, $\left.1.4 \times 10^{-3} \mathrm{mmol}, 33 \%\right) .{ }^{1} \mathrm{H}$ NMR $\left(400 \mathrm{MHz}, \mathrm{C}_{2} \mathrm{D}_{2} \mathrm{Cl}_{4}\right.$, $393 \mathrm{~K}) \delta 10.1-8.95(\mathrm{~m}, 12 \mathrm{H}), 8.33-6.51(\mathrm{~s}, 10 \mathrm{H}), 4.37-2.96(\mathrm{~m}$, 24H), 1.54-0.80 (m, 228H). IR (ATR): 2958, 2920, 2898, 2868, $1723,1619,1461,1260,1088,801 \mathrm{~cm}^{-1}$. HRMS (APCI-MS, $\left.m / z\right)=$ $3084.1392\left(\mathrm{M}^{+}\right)$; calcd for $\mathrm{C}_{234} \mathrm{H}_{274}: 3084.1441$.

pinB-GNR. To GNR-ref $\left(7.2 \mathrm{mg}, 2.3 \times 10^{-3} \mathrm{mmol}\right)$ and pinacolborane $(0.020 \mathrm{~mL}, 0.138 \mathrm{mmol})$ in 1,4-dioxane $(1 \mathrm{~mL})$ were added dtbpy $\left(1.7 \mathrm{mg}, 6.3 \times 10^{-3} \mathrm{mmol}\right)$ and $[\operatorname{Ir}(\mathrm{OMe}) \operatorname{cod}]_{2}$ $\left(1.6 \mathrm{mg}, 2.7 \times 10^{-3} \mathrm{mmol}\right)$ under an argon atmosphere. The reaction mixture was heated at $100{ }^{\circ} \mathrm{C}$ with stirring for $18 \mathrm{~h}$. The mixture was washed with water, extracted with dichloromethane and dried with $\mathrm{MgSO}_{4}$. Then, solvent was removed under vacuum and the solid residue was reprecipitated (dichloromethane/methanol), yielding a yellow solid. The crude product $(6.8 \mathrm{mg})$ was used without any further purification in the next step.

ZnP-GNR. To ZnP-Br $\left(5.5 \mathrm{mg}, 5.0 \times 10^{-3} \mathrm{mmol}\right)$ and pinBGNR $(6.8 \mathrm{mg})$ in toluene $(0.5 \mathrm{~mL})$ were added $\mathrm{Pd}\left(\mathrm{PPh}_{3}\right)_{4}(0.6 \mathrm{mg}$, $\left.5 \times 10^{-4} \mathrm{mmol}\right)$ and $\mathrm{Cs}_{2} \mathrm{CO}_{3}\left(6.8 \mathrm{mg}, 2.1 \times 10^{-2} \mathrm{mmol}\right)$ under an argon atmosphere. The reaction mixture was heated at $100{ }^{\circ} \mathrm{C}$ with stirring for $24 \mathrm{~h}$. The mixture was washed with water, extracted with dichloromethane and dried with $\mathrm{MgSO}_{4}$. Then, solvent was removed under vacuum and the solid residue was purified by column chromatography $\left(\mathrm{SiO}_{2}\right.$, dichloromethane : hexane $=1: 2$ ) and gel permeation chromatography (toluene), yielding ZnP-GNR as a deep red solid $(2.2 \mathrm{mg}$, $\left.4.3 \times 10^{-4} \mathrm{mmol}, 22 \%\right) .{ }^{1} \mathrm{H}$ NMR $\left(400 \mathrm{MHz}, \mathrm{C}_{2} \mathrm{D}_{2} \mathrm{Cl}_{4} 393 \mathrm{~K}\right)$ $\delta 10.01-9.62(\mathrm{~m}, 12 \mathrm{H}), 9.21-8.95(\mathrm{~m}, 16 \mathrm{H}), 8.62(\mathrm{~s}, 4 \mathrm{H}), 8.08(\mathrm{~d}, J$ $=15.2 \mathrm{~Hz} 12 \mathrm{H}), 7.77(\mathrm{~s}, 10 \mathrm{H}), 7.17-7.05(\mathrm{~m}, 8 \mathrm{H}), 3.57-3.35(\mathrm{~m}$, 24H), 2.25-0.88 (m, 336H). IR (ATR): 2950, 2932, 2919, 2859, $1717,1617,1554,1456,1363,1260,1086,803 \mathrm{~cm}^{-1}$. HRMS $($ MALDI-TOFMS, $m / z)=5105.1846\left(\mathrm{M}^{\cdot+}\right) ;$ calcd for $\mathrm{C}_{370} \mathrm{H}_{446} \mathrm{~N}_{8} \mathrm{Zn}_{2}:$ 5105.1850.

\section{Results and discussion}

Synthetic procedures are depicted in Scheme 1. HBC-ref and GNR-ref were prepared by a conventional intramolecular oxidation reaction of the corresponding oligo( $p$-phenylene)s (HPB and PPB-HPB-PPB) with $\mathrm{FeCl}_{3}$ as an oxidant. The iridium-catalyzed borylation reaction was applied to the less hindered $\mathrm{C}-\mathrm{H}$ groups of HBC-ref and GNR-ref, ${ }^{17}$ and then the Suzuki coupling reactions between the bis-borylated nanographenes (pinB-HBC and pinB-GNR) and zinc-porphyrins with a $p$-bromophenyl group at a meso-position ( $\mathrm{ZnP}-\mathrm{Br}$ ) were conducted to yield $\mathrm{ZnP}-$ HBC and ZnP-GNR, respectively. The UV-visible absorption spectra of ZnP-HBC and ZnP-GNR are largely the sum of the spectra of HBC-ref/GNR-ref and a porphyrin reference (5,10,15,20-tetrakis(3,5-di-tert-butylphenyl)-porphyrinatozinc(II),

ZnP-ref) (Fig. 1). The Soret bands of ZnP-HBC and ZnP-GNR are slightly red-shifted by $c a .2 \mathrm{~nm}$ compared to that of ZnP-ref. Bearing in mind that two $\mathrm{ZnP}$ units are present in $\mathrm{ZnP}-\mathrm{HBC}$ and $\mathrm{ZnP}-\mathrm{GNR}$, the extinction coefficients $(\varepsilon)$ at the maxima of the
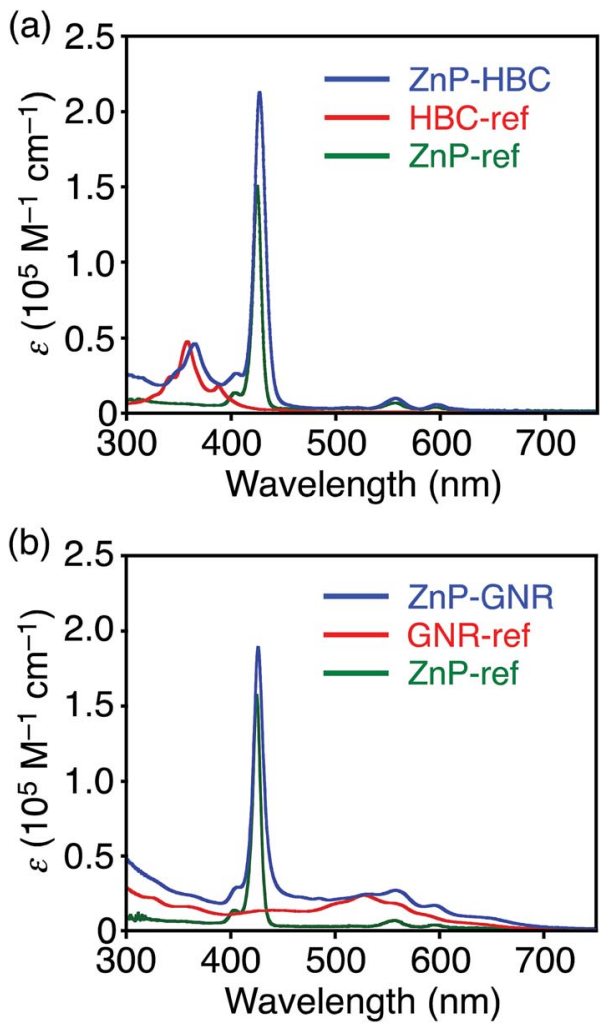

Fig. 1 UV-visible absorption spectra of (a) ZnP-HBC (blue), HBC-ref (red), ZnP-ref (green), (b) ZnP-GNR (blue), GNR-ref (red), and ZnP-ref (green) in THF.

Soret bands are decreased by $30 \%$ and $44 \%$ with respect to ZnPref (Fig. S1 $\dagger$ ), indicating that the interaction between the $\mathrm{ZnP}$ and nanographene moieties in the ground state is moderate and more pronounced in ZnP-GNR than in ZnP-HBC due to the larger size of the GNR unit than the HBC unit.

To evaluate the interactions between $\mathrm{ZnP}$ and $\mathrm{HBC}$ units in the excited states of $\mathrm{ZnP}-\mathrm{HBC}$, we measured steady-state fluorescence spectra of $\mathrm{ZnP}-\mathrm{HBC}$ and the references (Fig. 2 and $\mathrm{S} 2 \dagger)$. When ZnP-HBC and ZnP-ref were excited at $\lambda_{\mathrm{ex}}=426 \mathrm{~nm}$, where the absorbances were adjusted to be identical, the emission spectra showed comparable shapes and intensities (Fig. S2 $\uparrow$ ). Since the HBC moiety has almost no absorbance at $426 \mathrm{~nm}\left(\varepsilon<3.0 \times 10^{3} \mathrm{M}^{-1} \mathrm{~cm}^{-1}\right)$, the $\mathrm{ZnP}$ moieties $(\varepsilon=2.1 \times$ $10^{5} \mathrm{M}^{-1} \mathrm{~cm}^{-1}$ ) in ZnP-HBC predominantly absorb the excitation light and emit with negligible interaction with the HBC moiety. In contrast, HBC-ref showed a strong emission in the region of $460-600 \mathrm{~nm}$ with multiple peaks $\left(\lambda_{\mathrm{ex}}=360 \mathrm{~nm}\right.$, Fig. 2). However, the fluorescence spectrum of $\mathrm{ZnP}-\mathrm{HBC}$, where the absorption ratio of $\mathrm{ZnP}$ and $\mathrm{HBC}$ is $1: 4\left(\lambda_{\mathrm{ex}}=360 \mathrm{~nm}\right)$, exhibited two broad peaks at 604 and $656 \mathrm{~nm}$ (Fig. 2) with efficient quenching of the emission from the HBC unit. This spectrum matches with that of ZnP-ref. In addition, the nanosecond fluorescence lifetime $(\tau)$ of the $\mathrm{ZnP}$ moiety in $\mathrm{ZnP}-\mathrm{HBC}$ $(2.0 \mathrm{~ns}(100 \%))$, excited mainly at the HBC moiety, was similar to that of ZnP-ref (2.1 ns (100\%)), but differed significantly from those of HBC-ref (4.6 ns (8\%) and $43 \mathrm{~ns}(92 \%))^{28}$ (Fig. S3†). These results demonstrate the occurrence of EnT from the first 


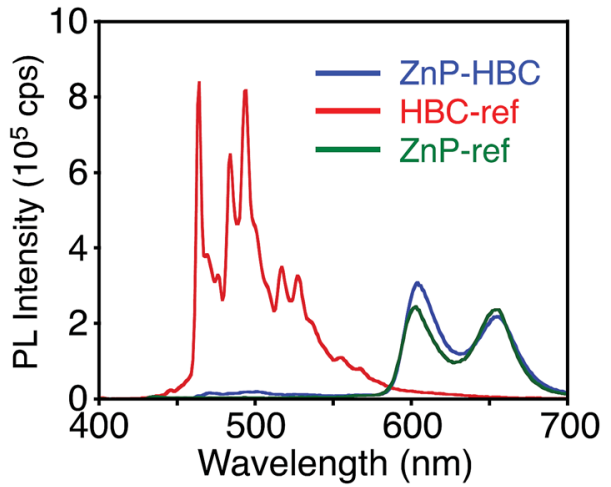

Fig. 2 Fluorescence spectra of $\mathrm{ZnP}-\mathrm{HBC}$ (blue), HBC-ref (red), and $\mathrm{ZnP}$-ref (green) in THF. The $\lambda_{\text {ex }}$ values are $360 \mathrm{~nm}$, where the absorbances are identical.

singlet excited state $\left(\mathrm{S}_{1}\right)$ of $\mathrm{HBC}\left({ }^{1} \mathrm{HBC}^{*}\right)$ to $\mathrm{ZnP}$ in $\mathrm{ZnP}-\mathrm{HBC}$, as reported in other porphyrin-HBC linked systems. ${ }^{11}$ The occurrence of EnT is reasonable because the optical bandgap of the HBC moiety $(2.73 \mathrm{eV})$ is larger than that of the ZnP moiety $(2.03$ $\mathrm{eV})$. Furthermore, the fluorescence intensities of ZnP-HBC and ZnP-ref with the same absorbance at $\lambda_{\mathrm{ex}}=360 \mathrm{~nm}$ are virtually the same (Fig. 2), indicating the highly efficient, exclusive EnT. In the picosecond fluorescence of the $\mathrm{ZnP}$ moiety in $\mathrm{ZnP}-\mathrm{HBC}$, a rise component ( $\tau=45 \mathrm{ps}$ ) was observed (Fig. S4 $\dagger$ ). This corresponds to an EnT rate constant $\left(k_{\mathrm{EnT}}\right)$ of $2.2 \times 10^{10} \mathrm{~s}^{-1}$. Given the average lifetime of ${ }^{1} \mathrm{HBC}^{*}$ in HBC-ref (40 ns), the quantum efficiency $\left(\varphi_{\mathrm{EnT}}\right)$ of EnT from ${ }^{1} \mathrm{HBC}^{*}$ to $\mathrm{ZnP}$ in $\mathrm{ZnP}-$ HBC was estimated to be unity (100\%).

DFT calculations also disclosed the larger bandgap of the HBC moiety than that of the ZnP moieties in ZnP-HBC (Fig. S5†). In addition, both the HOMO and LUMO of ZnP-HBC are distributed solely on the ZnP moieties (Fig. S5†). Considering the HOMO and LUMO energy levels experimentally estimated by electrochemical measurements and the optical bandgaps of $\mathrm{HBC}$ and $\mathrm{ZnP}$, ET from ${ }^{1} \mathrm{HBC}^{*}$ to $\mathrm{ZnP}$ is also energetically favorable with a driving force $\left(-\Delta G_{\mathrm{ET}}\right)$ of $0.54 \mathrm{eV}$ in THF (Fig. S6 $\dagger$ ). To get a thorough insight into the interaction between HBC and $\mathrm{ZnP}$ in the excited states, femto- to picosecond time-resolved transient absorption (TA) spectra measurements for $\mathrm{ZnP}-\mathrm{HBC}$ and $\mathrm{HBC}-$ ref were conducted at $\lambda_{\mathrm{ex}}$ $=360 \mathrm{~nm}$ (Fig. 3). The TA spectrum of HBC-ref revealed a positive absorption signal with a peak around $550 \mathrm{~nm}$ corresponding to ${ }^{1} \mathrm{HBC}^{*}$ (Fig. 3b), ${ }^{3 c}$ which has a lifetime longer than the limit of the detection system (6 ns). Meanwhile, even though the HBC moiety in ZnP-HBC was mainly excited, the positive peak at $550 \mathrm{~nm}$ was not evident even at 0.2 ps delay (Fig. 3a). The TA spectra of ZnP-HBC at 0.2 and 5 ps delays are similar to the sum of the TA spectra of HBC-ref (Fig. 3b) and ZnP-ref (Fig. S7 $\dagger$ ). The TA spectral shapes at $100 \mathrm{ps}$ and $2.1 \mathrm{~ns}$ coincide well with those of ZnP-ref, corresponding to the singlet $\left({ }^{1} \mathrm{ZnP}^{*}\right)$ and triplet $\left({ }^{3} \mathrm{ZnP} *\right)$ excited states of $\mathrm{ZnP}$. The characteristic TA signal for the porphyrin radical anion ( $\mathrm{ZnP}^{{ }^{--}}$) at $700-750 \mathrm{~nm}$ (ref. 29) was absent in the TA spectrum of ZnP-HBC, implying no occurrence of ET. This result agrees with the high $\varphi_{\mathrm{EnT}}$ value of
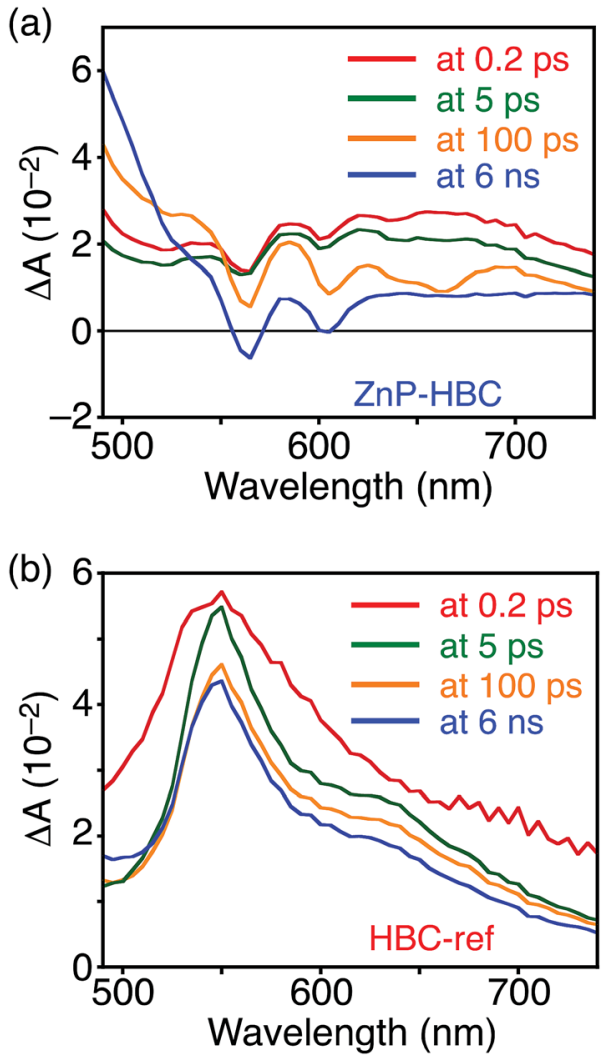

Fig. 3 Femto- to picosecond time-resolved TA spectra of (a) ZnP$\mathrm{HBC}$ and (b) HBC-ref in THF ( $\left.\lambda_{\mathrm{ex}}=360 \mathrm{~nm}\right)$. The delay times of $0.2 \mathrm{ps}$ to $6 \mathrm{~ns}$ are shown.

EnT from ${ }^{1} \mathrm{HBC}^{*}$ to $\mathrm{ZnP}$ as estimated by the fluorescence analysis. Four decay components were obtained from the global fitting of the TA data for ZnP-HBC (Fig. 4): the transition from the second $\left(\mathrm{S}_{2}\right)$ to first $\left(\mathrm{S}_{1}\right)$ singlet excited state of $\mathrm{ZnP}\left(\tau_{1}=1.3\right.$ ps), EnT from ${ }^{1} \mathrm{HBC}^{*}$ to $\mathrm{ZnP}\left(\tau_{2}=49 \mathrm{ps}\right)$, the decay of ${ }^{1} \mathrm{ZnP} *\left(\tau_{3}\right.$ $=1.7 \mathrm{~ns})$, and that of ${ }^{3} \mathrm{ZnP} *\left(\tau_{4}>10 \mathrm{~ns}\right)$. The $k_{\mathrm{EnT}}$ value estimated by TA $\left(2.0 \times 10^{10} \mathrm{~s}^{-1}\right)$ also matches well with that obtained from the fluorescence rise component $\left(2.2 \times 10^{10} \mathrm{~s}^{-1}\right.$,

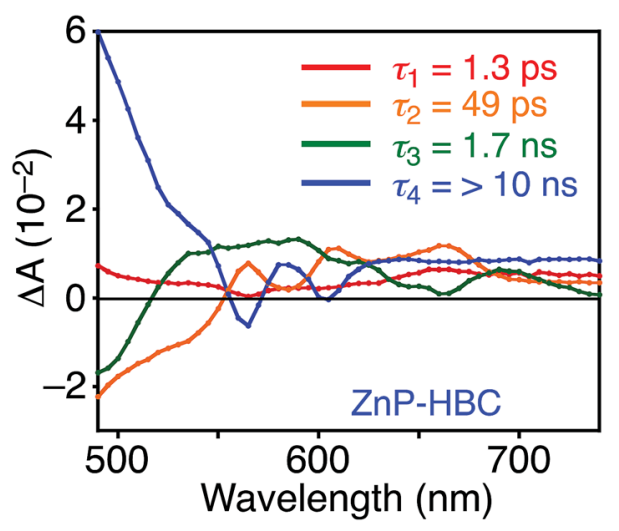

Fig. 4 Femto- to picosecond transient absorption decay component spectra of $\mathrm{ZnP}-\mathrm{HBC}$ in THF obtained with global four component fit of the data. The excitation wavelength is $360 \mathrm{~nm}$. Lifetimes of respective components are given in the figures. 
Fig. S4 $\dagger$ ). This rapid EnT may prevail over ET from ${ }^{1} \mathrm{HBC}^{*}$ to ZnP to generate the $\mathrm{HBC}$ radical cation and $\mathrm{ZnP}^{\cdot-}$, although $\mathrm{ET}$ is also energetically favorable.

The nano- to microsecond time-resolved TA spectrum of $\mathrm{ZnP}-\mathrm{HBC}$ at $10 \mu \mathrm{s}$ after the photoexcitation of the HBC moiety corresponded to that of ${ }^{3} \mathrm{ZnP} *$ with a peak at $840 \mathrm{~nm}$ (Fig. S8 $\dagger$ ). The monoexponential decay of the TA signal without forming any subsequent TA signifies a direct relaxation of ${ }^{3} \mathrm{ZnP}^{*}$ to the ground state. The energy levels of ${ }^{3} \mathrm{HBC}^{*}$ and ${ }^{3} \mathrm{ZnP}^{*}$ were determined using the phosphorescence spectra in frozen 2methyltetrahydrofuran glass at $77 \mathrm{~K}$ (ref. 30 and 31), and the relaxation pathways of $\mathrm{ZnP}-\mathrm{HBC}$ are summarized in Fig. S9. $\dagger$

Unlike ZnP-HBC, the fluorescence spectrum of ZnP-GNR with the Soret band excitation bears a remarkable resemblance to that of GNR-ref (Fig. 5). Consistently, the nanosecond fluorescence lifetimes and the component ratio of $\mathrm{ZnP}-\mathrm{GNR}$ (2.7 ns $(60 \%)$ and $25 \mathrm{~ns}(40 \%)$ ) at $\lambda_{\mathrm{ex}}=416 \mathrm{~nm}$ (absorption ratio, $\mathrm{ZnP}: \mathrm{GNR}=5: 1)$ and a detection wavelength $\left(\lambda_{\text {obs }}\right)$ of $650 \mathrm{~nm}$ were virtually identical with those of GNR-ref (3.0 ns (64\%) and $27 \mathrm{~ns}(36 \%)$ ) (Fig. S10 $\dagger$ ), but were totally different from that of ZnP-ref (2.0 ns (100\%)). These results indicate that the efficient EnT from ${ }^{1} \mathrm{ZnP}^{*}$ to GNR also takes place in $\mathrm{ZnP}-\mathrm{GNR}$, which is in the opposite direction from that observed in $\mathrm{ZnP}-\mathrm{HBC}$ and other porphyrin-linked HBCs. ${ }^{11}$ To the best of our knowledge, this is the first example of well-defined nanographene as an energy acceptor in covalently linked donor-acceptor systems. The reverse EnT results from the narrowed optical bandgap of the GNR moiety $(1.84 \mathrm{eV})$ arising from the rectangularly extended $\pi$-conjugation from HBC. A clear rise component with $\tau=0.2$ ps was detected in the picosecond fluorescence profile of ZnP-GNR at $\lambda_{\mathrm{ex}}=425 \mathrm{~nm}$ and $\lambda_{\mathrm{obs}}=650 \mathrm{~nm}$, where the absorption ratio of $\mathrm{ZnP}$ and GNR is $6: 1$ (Fig. S11†). This corresponds to a $k_{\mathrm{EnT}}$ of $5 \times 10^{12} \mathrm{~s}^{-1}$, which is much larger than the rate of EnT from ${ }^{1} \mathrm{HBC}^{*}$ to $\mathrm{ZnP}\left(k_{\mathrm{EnT}}\right.$ of $2.2 \times 10^{10} \mathrm{~s}^{-1}$, Fig. S4†). This ultrafast EnT indicates the violation of the Kasha's rule; EnT takes place mainly from the $\mathrm{S}_{2}$ state of ${ }^{1} \mathrm{ZnP}^{*}$ to GNR, taking into account the internal conversion rate constant of $\mathrm{S}_{2}$ to $\mathrm{S}_{1}$ of ${ }^{1} \mathrm{ZnP}^{*}\left(6.7 \times 10^{11} \mathrm{~s}^{-1}\right.$, Fig. S7b $\left.\dagger\right)$. Although ultrafast ET from the $\mathrm{S}_{2}$ state of ${ }^{1} \mathrm{ZnP}^{*}$ to an acceptor in donor-acceptor linked systems has been frequently

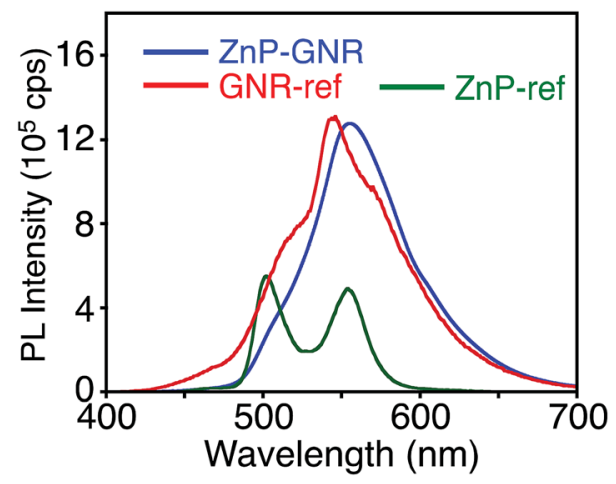

Fig. 5 Fluorescence spectra of ZnP-GNR (blue), GNR-ref (red), and ZnP-ref (green) in THF. The $\lambda_{\text {ex }}$ values are $422 \mathrm{~nm}$, where the absorbances are identical, respectively. observed, ${ }^{22 a, 32}$ the corresponding ultrafast EnT from the $\mathrm{S}_{2}$ state of ${ }^{1} \mathrm{ZnP}^{*}$ to an acceptor is rare. ${ }^{33}$ Meanwhile, in natural lightharvesting systems ultrafast EnT starting from carotenoids to chlorophylls is essential for efficient light-harvesting and subsequent charge separation. ${ }^{34}$

A DFT calculation provided an insight into the electronic state of ZnP-GNR, which revealed that the HOMO and LUMO are localized on the GNR moiety (Fig. S5 $\dagger$ ). This is in sharp contrast to $\mathrm{ZnP}-\mathrm{HBC}$, where the HOMO and LUMO are localized on the ZnP moieties (Fig. S5 $\dagger$ ). Considering the experimentally estimated HOMO and LUMO energy levels and optical bandgaps of the GNR and ZnP moieties, ETs from the singlet excited state of GNR $\left({ }^{1} \mathrm{GNR}^{*}\right)$ to $\mathrm{ZnP}\left(-\Delta G_{\mathrm{ET}}=0.04 \mathrm{eV}\right.$ in $\left.\mathrm{THF}\right)$ and from GNR to ${ }^{1} \mathrm{ZnP} *\left(-\Delta G_{\mathrm{ET}}=0.23 \mathrm{eV}\right.$ in THF) as well as EnT from ${ }^{1} \mathrm{ZnP}^{*}$ to GNR are energetically possible by the excitation of ZnP-GNR (Fig. S12 $\dagger$ ). To shed light on the possible ET and EnT processes, the TA spectra of $\mathrm{ZnP}-\mathrm{GNR}$ and GNR-ref were measured at $\lambda_{\text {ex }}=425 \mathrm{~nm}$ (Fig. 6). In contrast to HBC-ref, the TA spectra of GNR-ref did not show clear positive signals in the visible region, but exhibited a negative peak at $530 \mathrm{~nm}$ derived from the ground state absorption (Fig. 6b). Meanwhile, the TA spectra of ZnP-GNR largely resembled those of GNR-ref with a few exceptions (Fig. 6a). The TA spectrum of ZnP-GNR at 0.2 ps has features similar to that of ZnP-ref and GNR-ref at $0.2 \mathrm{ps}$ (Fig. S7 $\dagger$ ), implying the formation of the $\mathrm{S}_{2}$ state of ${ }^{1} \mathrm{ZnP} \mathrm{P}^{*}$ and ${ }^{1} \mathrm{GNR}^{*}$. The TA spectra at $5 \mathrm{ps}$ and $100 \mathrm{ps}$ exhibited a negative peak at $655 \mathrm{~nm}$, which is absent in the TA spectra of GNR-ref.
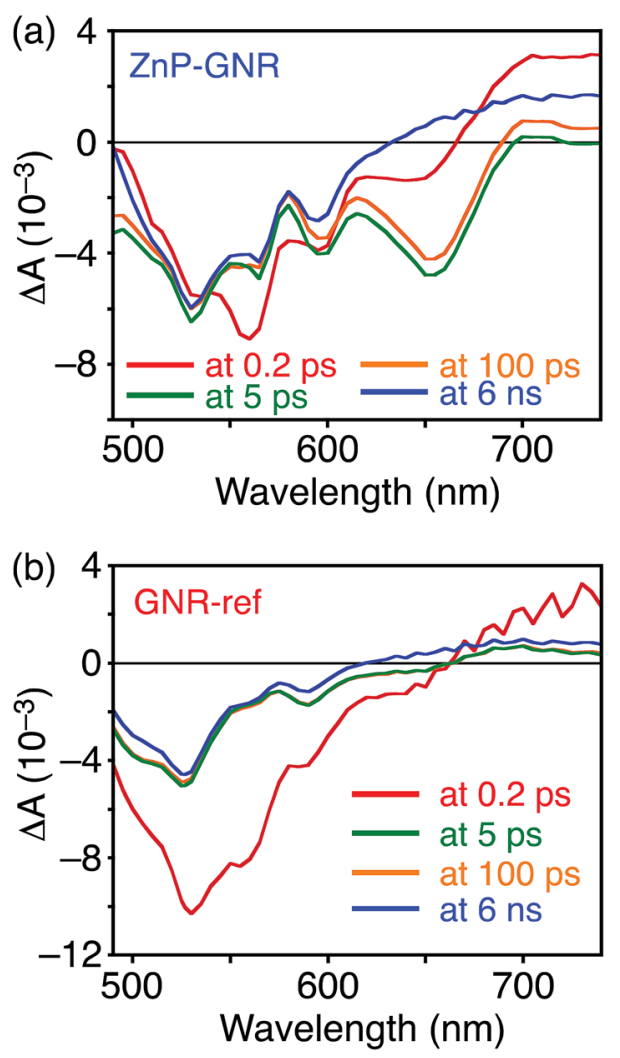

Fig. 6 Femto- to picosecond time-resolved TA spectra of (a) $\mathrm{ZnP}-$ GNR and (b) GNR-ref in THF ( $\lambda_{\text {ex }}=425 \mathrm{~nm}$ ). The delay times of $0.2 \mathrm{ps}$ to 6 ns are shown. 
Four components with $\tau_{1}=0.2 \mathrm{ps}, \tau_{2}=7.0 \mathrm{ps}, \tau_{3}=3.2 \mathrm{~ns}$, and $\tau_{4}$ $>10 \mathrm{~ns}$ were extracted from the TA spectra of ZnP-GNR (Fig. 7). No characteristic signals of $\mathrm{ZnP}^{\cdot-}$ (ref. 29) were observed, supporting no occurrence of ET from GNR to ZnP.

The first TA decay component $\left(\tau_{1}=0.2 \mathrm{ps}\right)$ corresponds to the rise component ( $\tau=0.2 \mathrm{ps}$ ) in the picosecond fluorescence decay, which reflects the ultrafast EnT from the $\mathrm{S}_{2}$ state of ${ }^{1} \mathrm{ZnP}^{*}$ to GNR. Given the good agreement between the second components of the fluorescence lifetime $\left(\tau_{2}=6.5 \mathrm{ps}\right.$, Fig. S11 $\left.\dagger\right)$ and TA $\left(\tau_{2}=\right.$ 7.0 ps, Fig. 7), EnT from the $S_{1}$ state of ${ }^{1} \mathrm{ZnP}^{*}$ to GNR also occurs with $k_{\mathrm{EnT}}=1.5 \times 10^{11} \mathrm{~s}^{-1}$. The overall $\varphi_{\mathrm{EnT}}$ of EnT from ${ }^{1} \mathrm{ZnP}^{*}\left(\mathrm{~S}_{2}\right.$ and $\mathrm{S}_{1}$ ) to GNR in $\mathrm{ZnP}-\mathrm{GNR}$ is unity considering the ultrafast EnTs, exceeding the energetically favorable ET from ${ }^{1} \mathrm{ZnP}^{*}$ to $\operatorname{GNR}\left(-\Delta G_{\mathrm{ET}}=0.23 \mathrm{eV}\right)$. ET from ${ }^{1} \mathrm{GNR}^{*}$ to $\mathrm{ZnP}$ was also absent probably due to the insufficient driving force $\left(-\Delta G_{\mathrm{ET}}=0.04 \mathrm{eV}\right)$. The negative peak at $655 \mathrm{~nm}$ in the second decay component spectrum of ZnP-GNR is presumably ascribed to the bleaching of the ground state absorption of the GNR moiety in ZnP-GNR, thereby supporting the formation of ${ }^{1} \mathrm{GNR} *$. Indeed, the corresponding ground-state absorption at $655 \mathrm{~nm}$ is enhanced in $\mathrm{ZnP}-$ GNR relative to that in GNR-ref (Fig. S13 $\dagger$ ). The peripheral functionalization of the GNR unit with $\mathrm{ZnP}$ through the $p$-phenylene bridge may influence the electronic state of the GNR edge structure, causing the difference in the absorption behaviors of ZnP-GNR and GNR-ref. Nevertheless, the TA spectrum of ZnPGNR at $6 \mathrm{~ns}$ is almost identical with that of GNR-ref at $6 \mathrm{~ns}$ (Fig. 6), suggesting the exclusive formation of the excited state of GNR by the excitation of ZnP-GNR on this time scale. The third and fourth components of transient absorption decay of $\mathrm{ZnP}-$ GNR (Fig. 7) correspond to the decays of ${ }^{1} \mathrm{GNR}^{*}$. Consistently, the first components ( $\tau=2.7-3.0 \mathrm{~ns}$ ) of the nanosecond fluorescence decays of ZnP-GNR and GNR-ref (Fig. S10†) match well with the third decay component of TA of ZnP-GNR (Fig. 7). Nano- to microsecond resolved TA spectra of ZnP-GNR and GNR-ref revealed the direct relaxation of the triplet excited state of GNR $\left({ }^{3} \mathrm{GNR}^{*}\right)$ to the ground state (Fig. S14 $\dagger$ ). Although the energy level of ${ }^{3} \mathrm{GNR}^{*}$ remains obscure owing to the absence of the phosphorescence signal of GNR-ref at $77 \mathrm{~K}$, the relaxation pathways of ZnP-GNR are illustrated in Fig. S15. $\dagger$

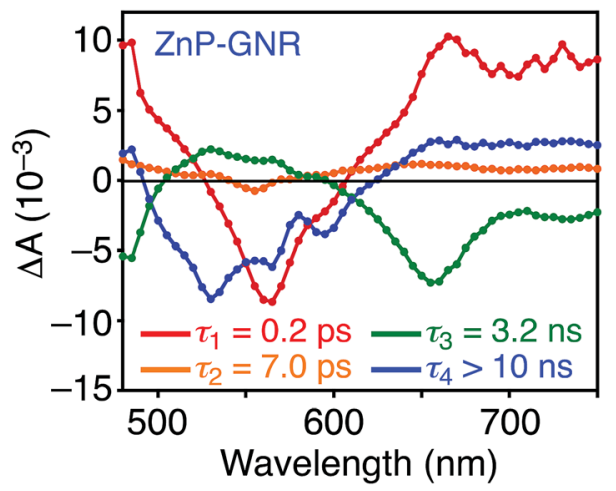

Fig. 7 Transient absorption decay component spectra of ZnP-GNR in THF obtained with global four component fit of the data. The excitation wavelength is $425 \mathrm{~nm}$. Lifetimes of respective components are given in the figures.
It is worthwhile to compare the photodynamics of porphyrinlinked graphenes and nanographenes. We previously reported ZnP-linked CCG with a $p$-phenylene bridge (ZnP-CCG) ${ }^{24}$ which showed entirely different photodynamic behavior from ZnPHBC and ZnP-GNR. The photoexcitation of the porphyrin moiety in $\mathrm{ZnP}-\mathrm{CCG}$ yielded an exciplex state, i.e., a mixed state of the locally excited states $\left({ }^{1} \mathrm{ZnP}^{*}\right.$ and $\left.{ }^{1} \mathrm{CCG}^{*}\right)$ and chargeseparated state $\left(\mathrm{ZnP}^{\cdot+}-\mathrm{CCG}^{\cdot-}\right)$, which rapidly decayed to the ground state. EnT from ${ }^{1} \mathrm{ZnP}^{*}$ to $\mathrm{CCG}$ as well as complete ET did not occur in ZnP-CCG. ${ }^{24}$ A stronger electronic coupling between $\mathrm{ZnP}$ and large graphenes than between $\mathrm{ZnP}$ and small nanographenes may facilitate the formation of the exciplex state in $\mathrm{ZnP}-\mathrm{CCG}{ }^{22,24}$ It is noteworthy that the $\mathrm{ZnP}$ groups stand on a graphene plane with a large tilt angle $\left(c a .49^{\circ}\right)$ in ZnP-CCG, whereas the $\mathrm{ZnP}$ moieties are attached to the nanographene at the periphery positions in $\mathrm{ZnP}-\mathrm{HBC}$ and $\mathrm{ZnP}-\mathrm{GNR}$. The difference in the mutual orientation of $\mathrm{ZnP}$ and graphenes or nanographenes may have an impact on the electronic coupling and dipole moment interaction and thereby the photodynamics.

\section{Conclusion}

In summary, porphyrins were covalently linked with welldefined nanographenes as graphene models at the periphery through a short, rigid $p$-phenylene spacer. Photoexcitation of the ZnP-HBC linked system led to exclusive EnT from the HBC first excited singlet state to $\mathrm{ZnP}$, whereas opposite selective EnT occurred from the ZnP second and first excited singlet states $\left(\mathrm{S}_{2}\right.$ and $\mathrm{S}_{1}$ ) to GNR in the $\mathrm{ZnP}-\mathrm{GNR}$ linked system. In particular, the ultrafast EnTs took place from both the $\mathrm{S}_{2}$ and $\mathrm{S}_{1}$ states of $\mathrm{ZnP}$, mimicking efficient light-harvesting and EnT from the $S_{2}$ and $S_{1}$ states of carotenoids to chlorophylls in natural photosynthesis. The size of the $\pi$-conjugation system in nanographenes influences the EnT direction with maintaining exclusive occurrence of EnT, although the reason for selective occurrence of EnT is unclear at this stage. In contrast to the covalently linked systems of $\mathrm{ZnP}$ and large, ununiform graphenes with a $p$-phenylene bridge, charge-separated and exciplex states were not formed in the present systems probably owing to the relatively weak electronic coupling between $\mathrm{ZnP}$ and nanographenes. The results demonstrate that the photophysical properties of photoactive molecule-graphene composites can be tuned by altering the size of the $\mathrm{sp}^{2}$ carbon network in graphenes and the attachment orientation of the photoactive molecule to the graphene plane. Such unique photophysical properties will be useful for their future practical applications in optoelectronic devices, photocatalysts, and biosensors.

\section{Conflicts of interest}

There are no conflicts to declare.

\section{Acknowledgements}

This work was supported by JSPS KAKENHI (Grant Number 18H03898). 


\section{Notes and references}

1 (a) L. Chen, Y. Hernandez, X. Feng and K. Müllen, Angew. Chem., Int. Ed., 2012, 51, 7640; (b) M. Ball, Y. Zhong, Y. Wu, C. Schenck, F. Ng, M. Steigerwald, S. Xiao and C. Nuckolls, Acc. Chem. Res., 2015, 48, 267; (c) A. Narita, X.-Y. Wang, X. Feng and K. Müllen, Chem. Soc. Rev., 2015, 44, 6616; (d) Y. Segawa, H. Ito and K. Itami, Nat. Rev. Mater., 2016, 1, 15002; (e) X.-Y. Wang, A. Narita and K. Müllen, Nat. Rev. Chem., 2017, 2, 0100.

2 (a) X. Yan, X. Cui, B. Li and L.-s. Li, Nano Lett., 2010, 10, 1869; (b) X. Yan, B. Li, X. Cui, Q. Wei, K. Tajima and L.-s. Li, J. Phys. Chem. Lett., 2011, 2, 1119; (c) X. Yan, B. Li and L.-s. Li, Acc. Chem. Res., 2013, 46, 2254.

3 (a) M. L. Mueller, X. Yan, J. A. McGuire and L.-s. Li, Nano Lett., 2010, 10, 2679; (b) L. Cao, M. J. Meziani, S. Sahu and Y.-P. Sun, Acc. Chem. Res., 2013, 46, 171; (c) S. Zhu, L. Wang, B. Li, Y. Song, X. Zhao, G. Zhang, S. Zhang, S. Lu, J. Zhang, H. Wang, H. Sun and B. Yang, Carbon, 2014, 77, 462; (d) M. Daigle, A. Picard-Lafond, E. Soligo and J.-F. Morin, Angew. Chem., Int. Ed., 2016, 55, 2042; (e) H. Hayashi, N. Aratani and H. Yamada, Chem.-Eur. J., 2017, 23, 7000.

4 (a) A. M. van de Craats, J. M. Warman, A. Fechtenkötter, J. D. Brand, M. A. Harbison and K. Müllen, Adv. Mater., 1999, 11, 1469; (b) M. G. Debije, J. Piris, M. P. de Haas, J. M. Warman, Ž. Tomović, C. D. Simpson, M. D. Watson and K. Müllen, J. Am. Chem. Soc., 2004, 126, 4641; (c) J. Wu, W. Pisula and K. Müllen, Chem. Rev., 2007, 107, 718.

5 (a) C. Soldano, A. Mahmood and E. Dujardin, Carbon, 2010, 48, 2127; (b) X. Li, M. Rui, J. Song, Z. Shen and H. Zeng, Adv. Funct. Mater., 2015, 25, 4929.

6 V. V. Jarikov, J. Appl. Phys., 2006, 100, 014901.

7 (a) L. Schmidt-Mende, A. Fechtenkötter, K. Müllen, E. Moons, R. H. Friend and J. D. MacKenzie, Science, 2001, 293, 1119; (b) S. J. Kang, S. Ahn, J. B. Kim, C. Schenck, A. M. Hiszpanski, S. Oh, T. Schiros, Y.-L. Loo and C. Nuckolls, J. Am. Chem. Soc., 2013, 135, 2207; (c) J. Cao, Y.-M. Liu, X. Jing, J. Yin, J. Li, B. Xu, Y.-Z. Tan and N. Zheng, J. Am. Chem. Soc., 2015, 137, 10914; (d) K. P. Loh, S. W. Tong and J. Wu, J. Am. Chem. Soc., 2016, 138, 1095.

8 (a) W. Pisula, A. Menon, M. Stepputat, I. Lieberwirth, U. Kolb, A. Tracz, H. Sirringhaus, T. Pakula and K. Müllen, Adv. Mater., 2005, 17, 684; (b) I. O. Shklyarevskiy, P. Jonkheijm, N. Stutzmann, D. Wasserberg, H. J. Wondergem, P. C. M. Christianen, A. P. H. J. Schenning, D. M. de Leeuw, Ž. Tomović, J. Wu, K. Müllen and J. C. Maan, J. Am. Chem. Soc., 2005, 127, 16233; (c) A. N. Abbas, B. Liu, A. Narita, L. F. Dössel, B. Yang, W. Zhang, J. Tang, K. L. Wang, H. J. Räder, X. Feng, K. Müllen and C. Zhou, J. Am. Chem. Soc., 2015, 137, 4453.

9 (a) J. Wu, M. D. Watson and K. Müllen, Angew. Chem., Int. Ed., 2003, 42, 5329; (b) H. Seyler, B. Purushothaman, D. J. Jones, A. B. Holmes and W. W. H. Wong, Pure Appl. Chem., 2012, 84, 1047.
10 (a) M. J. Allen, V. C. Tung and R. B. Kaner, Chem. Rev., 2010, 110, 132; (b) K. S. Novoselov, V. I. Fal'ko, L. Colombo, P. R. Gellert, M. G. Schwab and K. Kim, Nature, 2012, 490, 192; (c) D. R. Dreyer, S. Park, C. W. Bielawski and R. S. Ruoff, Chem. Soc. Rev., 2010, 39, 228; (d) S. Gambhir, R. Jalili, D. L. Officer and G. G. Wallace, NPG Asia Mater., 2015, 7, e186; (e) S. Pei and H.-M. Cheng, Carbon, 2012, 50, 3210; (f) J. Shen, Y. Zhu, X. Yang and C. Li, Chem. Commun., 2012, 48, 3686.

11 (a) W. W. H. Wong, T. Khoury, D. Vak, C. Yan, D. J. Jones, M. J. Crossley and A. B. Holmes, J. Mater. Chem., 2010, 20, 7005; (b) J. M. Englert, J. Malig, A. V. Zamolo, A. Hirsch and N. Jux, Chem. Commun., 2013, 49, 4827; (c) D. Lungerich, J. F. Hitzenberger, M. Marcia, F. Hampel, T. Drewello and N. Jux, Angew. Chem., Int. Ed., 2014, 53, 12231; (d) D. Lungerich, J. F. Hitzenberger, W. Donaubauer, T. Drewello and N. Jux, Chem.-Eur. J., 2016, 22, 16755; (e) B. Limburg, J. O. Thomas, G. Holloway, H. Sadeghi, S. Sangtarash, I. C.-Y. Hou, J. Cremers, A. Narita, K. Müllen, C. J. Lambert, G. A. D. Briggs, J. A. Mol and H. L. Anderson, Adv. Funct. Mater., 2018, 28, 180326; (f) D. Lungerich, J. F. Hitzenberger, F. Hampel, T. Drewello and N. Jux, Chem.-Eur. J., 2018, 24, 15818.

12 (a) J. Wu, J. Qu, N. Tchebotareva and K. Müllen, Tetrahedron Lett., 2005, 46, 1565; (b) L. F. Dössel, V. Kamm, I. A. Howard, F. Laquai, W. Pisula, X. Feng, C. Li, M. Takase, T. Kudernac, S. D. Feyter and K. Müllen, J. Am. Chem. Soc., 2012, 134, 5876.

13 (a) W. W. H. Wong, D. Vak, T. B. Singh, S. Ren, C. Yan, D. J. Jones, I. I. Liaw, R. N. Lamb and A. B. Holmes, Org. Lett., 2010, 12, 5000; (b) A. Kratzer, J. M. Englert, D. Lungerich, F. W. Heinemann, N. Jux and A. Hirsch, Faraday Discuss., 2014, 173, 297.

14 A. Keerthi, I. C.-Y. Hou, T. Marszalek, W. Pisula, M. Baumgarten and A. Narita, Chem.-Asian J., 2016, 11, 2710. 15 (a) T. Böhme, C. D. Simpson, K. Müllen and J. P. Rabe, Chem.-Eur. J., 2007, 13, 7349; (b) X. Yang, X. Dou, A. Rouhanipour, L. Zhi, J. H. Räder and K. Müllen, J. Am. Chem. Soc., 2008, 130, 4216.

16 (a) C. D. Simpson, J. D. Brand, A. J. Berresheim, L. Przybilla, H. J Räder and K. Müllen, Chem.-Eur. J., 2002, 8, 1424; (b) K. Müllen, ACS Nano, 2014, 8, 6531.

17 R. Yamaguchi, S. Hiroto and H. Shinokubo, Org. Lett., 2012, 14, 2472.

18 (a) Y. Xu, Z. Liu, X. Zhang, Y. Wang, J. Tian, Y. Huang, Y. Ma, X. Zhang and Y. Chen, Adv. Mater., 2009, 21, 1275; (b) Z.-B. Liu, Y.-F. Xu, X.-Y. Zhang, X.-L. Zhang, Y.-S. Chen and J.-G. Tian, J. Phys. Chem. B, 2009, 113, 9681.

19 (a) P. Guo, P. Chen and M. Liu, ACS Appl. Mater. Interfaces, 2013, 5, 5336; (b) S. K. Das, C. B. Kc, K. Ohkubo, Y. Yamada, S. Fukuzumi and F. D'Souza, Chem. Commun., 2013, 49, 2013; (c) S. Su, J. Wang, E. Vargas, J. Wei, R. Martinez-Zaguilan, S. R. Sennoune, M. L. Pantoya, S. Wang, J. Chaudhuri and J. Qiu, ACS Biomater. Sci. Eng., 2016, 2, 1357.

20 (a) Y. Xu, L. Zhao, H. Bai, W. Hong, C. Li and G. Shi, J. Am. Chem. Soc., 2009, 131, 13490; (b) A. Wojcik and 
P. V. Kamat, ACS Nano, 2010, 4, 6697; (c) M. Jahan, O. Bao and K. P. Loh, J. Am. Chem. Soc., 2012, 134, 6707.

21 (a) Q. Lu, Y. Zhang and S. Liu, J. Mater. Chem. A, 2015, 3, 8552; (b) Y. Liu, S. Li, K. Li, Y. Zheng, M. Zhang, C. Cai, C. Yu, Y. Zhou and D. Yan, Chem. Commun., 2016, 52, 9394; (c) Y. Cao, H. Dong, Z. Yang, X. Zhong, Y. Chen, W. Dai and X. Zhang, ACS Appl. Mater. Interfaces, 2017, 9, 159.

22 (a) T. Umeyama and H. Imahori, J. Phys. Chem. C, 2013, 117, 3195; (b) T. Umeyama and H. Imahori, Nanoscale Horiz., 2018, 3, 352 .

23 (a) N. Karousis, A. S. D. Sandanayaka, T. Hasobe, S. P. Economopoulos, E. Sarantopouloua and N. Tagmatarchis, J. Mater. Chem., 2011, 21, 109; (b) H.-X. Wang, K.-G. Zhou, Y.-L. Xie, J. Zeng, N.-N. Chai, J. Li and H.-L. Zhang, Chem. Commun., 2011, 47, 5747; (c) M.-E. Ragoussi, G. Katsukis, A. Roth, J. Malig, G. de la Torre, D. M. Guldi and T. Torres, J. Am. Chem. Soc., 2014, 136, 4593.

24 (a) T. Umeyama, J. Mihara, N. Tezuka, Y. Matano, K. Stranius, V. Chukharev, N. V. Tkachenko, H. Lemmetyinen, K. Noda, K. Matsushige, T. Shishido, Z. Liu, K. Hirose-Takai, K. Suenaga and H. Imahori, Chem.-Eur. J., 2012, 18, 4250; (b) T. Umeyama, T. Hanaoka, J. Baek, T. Higashino, F. Abou-Chahine, N. V. Tkachenko and H. Imahori, J. Phys. Chem. C, 2016, 120, 28337.

25 N. V. Tkachenko, L. Rantala, A. Y. Tauber, J. Helaja, P. H. Hynninen and H. Lemmetyinen, J. Am. Chem. Soc., 1999, 121, 9378.

26 D. Sirbu, C. Turta, A. C. Benniston, F. Abou-Chahine, H. Lemmetyinen, N. V. Tkachenko, C. Wood and E. Gibson, RSC Adv., 2014, 4, 22733.

27 M. J. Frisch, G. W. Trucks, H. B. Schlegel, G. E. Scuseria, M. A. Robb, J. R. Cheeseman, G. Scalmani, V. Barone, B. Mennucci, G. A. Petersson, H. Nakatsuji, M. Caricato, X. Li, H. P. Hratchian, A. F. Izmaylov, J. Bloino, G. Zheng, J. L. Sonnenberg, M. Hada, M. Ehara, K. Toyota, R. Fukuda, J. Hasegawa, M. Ishida, T. Nakajima, Y. Honda,
O. Kitao, H. Nakai, T. Vreven, J. A. Montgomery Jr, J. E. Peralta, F. Ogliaro, M. Bearpark, J. J. Heyd, E. Brothers, K. N. Kudin, V. N. Staroverov, R. Kobayashi, J. Normand, K. Raghavachari, A. Rendell, J. C. Burant, S. S. Iyengar, J. Tomasi, M. Cossi, N. Rega, J. M. Millam, M. Klene, J. E. Knox, J. B. Cross, V. Bakken, C. Adamo, J. Jaramillo, R. Gomperts, R. E. Stratmann, O. Yazyev, A. J. Austin, R. Cammi, C. Pomelli, J. W. Ochterski, R. L. Martin, K. Morokuma, V. G. Zakrzewski, G. A. Voth, P. Salvador, J. J. Dannenberg, S. Dapprich, A. D. Daniels, Ö. Farkas, J. B. Foresman, J. V. Ortiz, J. Cioslowski and D. J. Fox, Gaussian 09, Gaussian, Inc., Wallingford CT, 2009. 28 K.-Y. Kim, S. Liu, M. E. Köse and K. S. Schanze, Inorg. Chem., 2006, 45, 2509.

29 J. G. Lanese and G. S. Wilson, J. Electrochem. Soc., 1972, 119, 1039.

30 B. E. Hamaoui, F. Laquai, S. Baluschev, J. Wu and K. Müllen, Synth. Met., 2006, 156, 1182.

31 S. K. Das, B. Song, A. Mahler, V. N. Nesterov, A. K. Wilson, O. Ito and F. D'Souza, J. Phys. Chem. C, 2014, 118, 3994.

32 (a) M. Andersson, J. Davidsson and L. Hammarström, J. Phys. Chem. B, 1999, 103, 3258; (b) N. Mataga, H. Chosrowjan, Y. Shibata, N. Yoshida, A. Osuka, T. Kikuzawa and T. Okada, J. Am. Chem. Soc., 2001, 123, 12422; (c) N. V. Tkachenko, H. Lemmetyinen, J. Sonoda, K. Ohkubo, T. Sato, H. Imahori and S. Fukuzumi, J. Phys. Chem. A, 2003, 107, 8834; (d) R. T. Hayes, C. J. Walsh and M. R. Wasielewski, J. Phys. Chem. A, 2004, 108, 2375; (e) K. Kiyosawa, N. Shiraishi, T. Shimada, D. Masui, H. Tachibana, S. Takagi, O. Ishitani, D. A. Tryk and H. Inoue, J. Phys. Chem. C, 2009, 113, 11667.

33 T. Kesti, N. Tkachenko, H. Yamada, H. Imahori, S. Fukuzumi and H. Lemmetyinen, Photochem. Photobiol. Sci., 2003, 2, 251.

34 (a) R. Croce, M. G. Müller, R. Bassi and A. R. Holzwarth, Biophys. J., 2001, 80, 901; (b) C. C. Gradinaru, I. H. M. van Stokkum, A. A. Pascal, R. van Grondelle and $H$. van Amerongen, J. Phys. Chem. B, 2000, 104, 9330. 